\title{
Analysis of the Survey on the Degree of Chinese Residents' Satisfaction with Government Service: A Study Based on Annual Survey Data
}

\author{
Ni Sun, Lei Feng, Ranran Zhao \\ Zhichun Road, Haidian District \\ China National Institute of Standardization \\ Beijing, China
}

\begin{abstract}
Residents' degree of satisfaction with the government is the focus of many current research projects. After surveying the degree of satisfaction with the government in 31 provinces (municipalities and autonomous regions) of the mainland for three consecutive years from 2015 to 2017, this study, finds that the overall degree of satisfaction scored around 60 points, which had been steadily climbing for three years in a row. The study also finds that urban residents are significantly more satisfied with the government than rural residents, and poor environmental quality is a major cause of dissatisfaction.
\end{abstract}

Keywords—social satisfaction; government work

\section{INTRODUCTION}

The government is the organization that enforces state powers and manages social and public affairs. The ultimate goal of government and its policies is to increase the gross national welfare. However, according to economists, government organizations and their roles are oftentimes like a double-edged sword: on the one hand, government has a role to play in making sure that the market is functioning through correcting the market failure. In particular, at the early stage of the market economy, the "visible hand" of the government is important to the establishment of market rules, market development, and the exercise of market regulation. On the other hand, government organizations might fail too when the market is well-functioning and sound, thereby damaging social welfare. Therefore, government organizations that can minimize the cost of market or government failures and maximize social welfare are optimal government organizations. One of the important indicators of the government quality is the degree of public satisfaction with government work.

\section{LITERATURE REVIEW}

Currently, residents' satisfaction with the government has become a focus and popular subject of interdisciplinary research in economics, sociology, psychology, etc. The World Values Survey (WVS), as one of the important sources of the data for subjective well-being research, uses questionnaire survey to investigate the subjective well-being of residents on a large scale. Respondents are often required to choose a number from 1 to 4 when asked "taking all the circumstances into account, are you happy now". 1 stands for the least happiness and 4 for the greatest happiness. Some scholars in recent years said that the Chinese economy is troubled by serious structural distortions in financial expenditure, as proportions of social expenditure such as education, health, and social security are too low, while the proportions of social expenditure such as administrative expenses are too high. Improving the quality of the government will improve the well-being of low-income residents (rural residents and residents living in central and western China), but will not significantly improve the well-being of high-income residents (urban residents and residents living in the eastern part of China).

\section{ReSEARCH METHOdOLOGY}

From May 2015 to October 2017, 235-277 staff members participated in the questionnaire survey each year by conducting random sampling of residents in 31 provinces (municipalities and autonomous regions) (having lived there for at least two years consecutively) nationwide. Through the processes of implementation, review, results quantization and statistical analysis of the questionnaire, the degree of residents' satisfaction with government services was evaluated. The residents' satisfaction with government service was measured in five aspects, namely, product quality, engineering quality, service quality, environmental quality and quality awareness. The number of valid questionnaires collected in 2015-2017 was $37,824,44,884$ and 44,884 , respectively.

\section{A. Distribution of Sample Size of Respondents}

The respondents were residents in 31 provinces (municipalities and autonomous regions) including Beijing, Tianjin, Hebei, Shanxi, Inner Mongolia, Liaoning, Jilin, Heilongjiang, Shanghai, Jiangsu, Zhejiang, Anhui, Fujian, Jiangxi, Shandong, Henan, Hubei, Hunan, Guangdong, Guangxi, Hainan, Chongqing, Sichuan, Guizhou, Yunnan, Tibet, Shaanxi, Gansu, Qinghai, Ningxia and Xinjiang. The respondents, aged between 18-79, had lived in the surveyed provinces for at least two years. The distribution of the valid sample size is shown in Table 1. 
TABLE I REgIONAL Distribution OF RESPONDENTS IN THE GOVERNMENT SERVICE SATISFACTION SURVEY

\begin{tabular}{|c|c|c|c|c|c|}
\hline Province & City & County/District & $\begin{array}{l}2015 \\
\text { Sample Size }\end{array}$ & $\begin{array}{l}\text { 2016 Sample } \\
\text { Size }\end{array}$ & $\begin{array}{l}2017 \\
\text { Sample Size }\end{array}$ \\
\hline Beijing & 4 & 12 & 960 & 1152 & 1152 \\
\hline Tianjin & 4 & 12 & 960 & 1152 & 1152 \\
\hline Hebei & 4 & 12 & 1536 & 1900 & 1900 \\
\hline Shanxi & 4 & 12 & 1152 & 1152 & 1152 \\
\hline Inner Mongolia & 4 & 12 & 960 & 1152 & 1152 \\
\hline Liaoning & 4 & 12 & 1344 & 1200 & 1200 \\
\hline Jilin & 4 & 12 & 1152 & 1152 & 1152 \\
\hline Heilongjiang & 4 & 12 & 1152 & 1152 & 1152 \\
\hline Shanghai & 4 & 12 & 960 & 1152 & 1152 \\
\hline Jiangsu & 4 & 12 & 1536 & 2100 & 2100 \\
\hline Zhejiang & 4 & 12 & 1344 & 1500 & 1500 \\
\hline Anhui & 4 & 12 & 1344 & 1600 & 1600 \\
\hline Fujian & 4 & 12 & 1152 & 1152 & 1152 \\
\hline Jiangxi & 4 & 12 & 1344 & 1200 & 1200 \\
\hline Shandong & 4 & 12 & 1536 & 2600 & 2600 \\
\hline Henan & 4 & 12 & 1536 & 2500 & 2500 \\
\hline Hubei & 4 & 12 & 1344 & 1500 & 1500 \\
\hline Hunan & 4 & 12 & 1536 & 1800 & 1800 \\
\hline Guangdong & 4 & 12 & 1536 & 2800 & 2800 \\
\hline Guangxi & 4 & 12 & 1344 & 1200 & 1200 \\
\hline Hainan & 4 & 12 & 960 & 1152 & 1152 \\
\hline Chongqing & 4 & 12 & 1152 & 1152 & 1152 \\
\hline Sichuan & 4 & 12 & 1536 & 2200 & 2200 \\
\hline Guizhou & 4 & 12 & 1152 & 1152 & 1152 \\
\hline Yunnan & 4 & 12 & 1344 & 1200 & 1200 \\
\hline Tibet & 4 & 12 & 960 & 1152 & 1152 \\
\hline Shaanxi & 4 & 12 & 1152 & 1152 & 1152 \\
\hline Gansu & 4 & 12 & 960 & 1152 & 1152 \\
\hline Qinghai & 4 & 12 & 960 & 1152 & 1152 \\
\hline Ningxia & 4 & 12 & 960 & 1152 & 1152 \\
\hline Xinjiang & 4 & 12 & 960 & 1152 & 1152 \\
\hline Total & 124 & 372 & 37824 & 44884 & 44884 \\
\hline
\end{tabular}

\section{B. Indicator System of Residents' Satisfaction with} Government Service

In this study, the indicators of residents' satisfaction with government service were designed after referring to Quality Work Assessment Method (G. B. F. [2013] No. 47). The questionnaire survey was conducted on five items: degree of residents' satisfaction with the government work in products, engineering, service, environment and residents' quality awareness. The five aspects were applied as the primary indicators, which were further categorized into secondary indicators. Then a questionnaire was designed out of the typical, perceptible and easy-to-evaluate contents concerning the indicators before using a Likert five-level scale for evaluation. Please refer to Table 2 for the specific indicator system. 
TABLE II INDICATORS OF RESIDENTS’ SATISFACTION WITH GOVERNMENT SERVICE

\begin{tabular}{|c|c|c|c|}
\hline \multirow{15}{*}{ 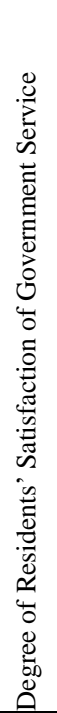 } & Primary Indicator & Secondary Indicator & Likert Scale \\
\hline & \multirow{5}{*}{ Product } & Food, medicine, and agricultural products & \multirow{14}{*}{$\begin{array}{l}\text { 1. Strongly dissatisfied (0) } \\
\text { 2. Dissatisfied (25) 3. Neither satisfied } \\
\text { nor dissatisfied (50) } \\
\text { 4. Satisfied (75)) } \\
\text { 5. Strongly satisfied (100) }\end{array}$} \\
\hline & & Durable consumer goods & \\
\hline & & Fast-moving consumer goods & \\
\hline & & Imported products & \\
\hline & & Special equipment & \\
\hline & \multirow{2}{*}{ Engineering } & Residential building & \\
\hline & & Traffic construction & \\
\hline & \multirow{2}{*}{ Service } & Productive service & \\
\hline & & Life service & \\
\hline & \multirow{2}{*}{ Environment } & Water environment & \\
\hline & & Air environment & \\
\hline & \multirow{3}{*}{ Quality awareness } & Residents' supervision of the government & \\
\hline & & Complaint about product quality & \\
\hline & & Government information publicity and disclosure & \\
\hline
\end{tabular}

\section{FINDINGS}

The result shows that the overall score of residents' satisfaction with government service was 61.53 in 2017, after rising steadily from 59.78 in 2015 for three years in a row.
Among the five indicators, engineering quality had been the highest since 2015, while environmental quality had always been the lowest. But the score of residents' quality awareness had witnessed the biggest increase and fasted progress in three years (Figure 1).

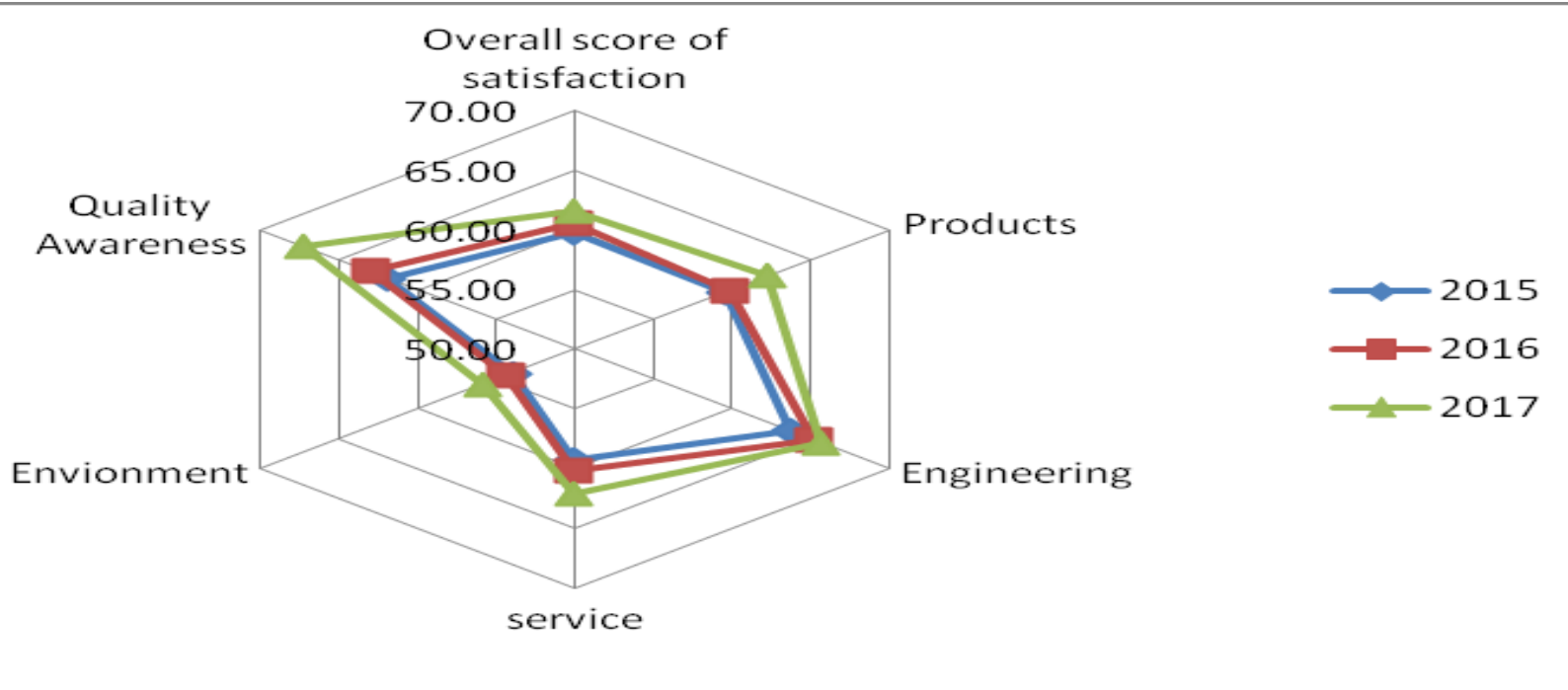

Fig. 1 Score of residents' satisfaction with government service from 2015 to 2017

\section{A. Product Quality}

The score of residents' satisfaction with product quality increased from 59.62 in 2015 to 59.88 in 2017, showing a trend of steady growth. Among them, the score of satisfaction with imported products was the highest for three consecutive years, which demonstrates that, to some extent, the quality of imported products is good. The score of satisfaction with agricultural products grew from 53.43 in 2015 to 60.37 in 2017 by $12.99 \%$, registering the largest increase among the five secondary indicators. The score of satisfaction with special equipment increased from 60.95 in 2015 to 64.08 in the 2017, registering quite remarkable growth (Figure 2). 


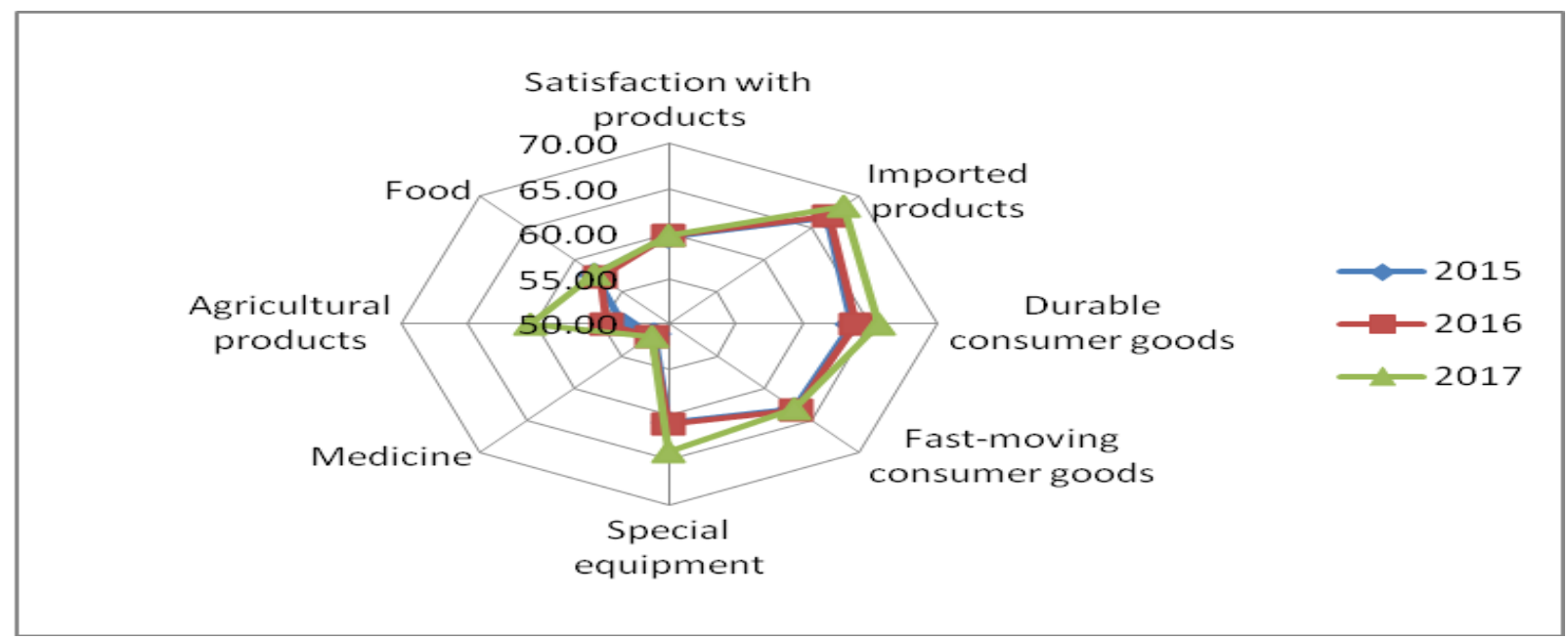

Fig. 2 Score of residents' satisfaction with products quality from 2015 to 2017

\section{B. Engineering Quality}

The score of residents' satisfaction with engineering quality increased steadily from 63.68 in 2015 to 65.61 in 2017 for three consecutive years. Among them, the highest in 2014 was the score of satisfaction with the quality of public buildings, i.e.
61.74. However, to optimize the survey indicators, the indicator of public building quality has been excluded from the survey since 2015. The score of residents' satisfaction with traffic construction project quality rose from 57.56 in 2014 to 67.42 in 2017 , while the score of residential building quality increased from 56.70 in 2014 to 66.27 in 2017 (Figure 3).

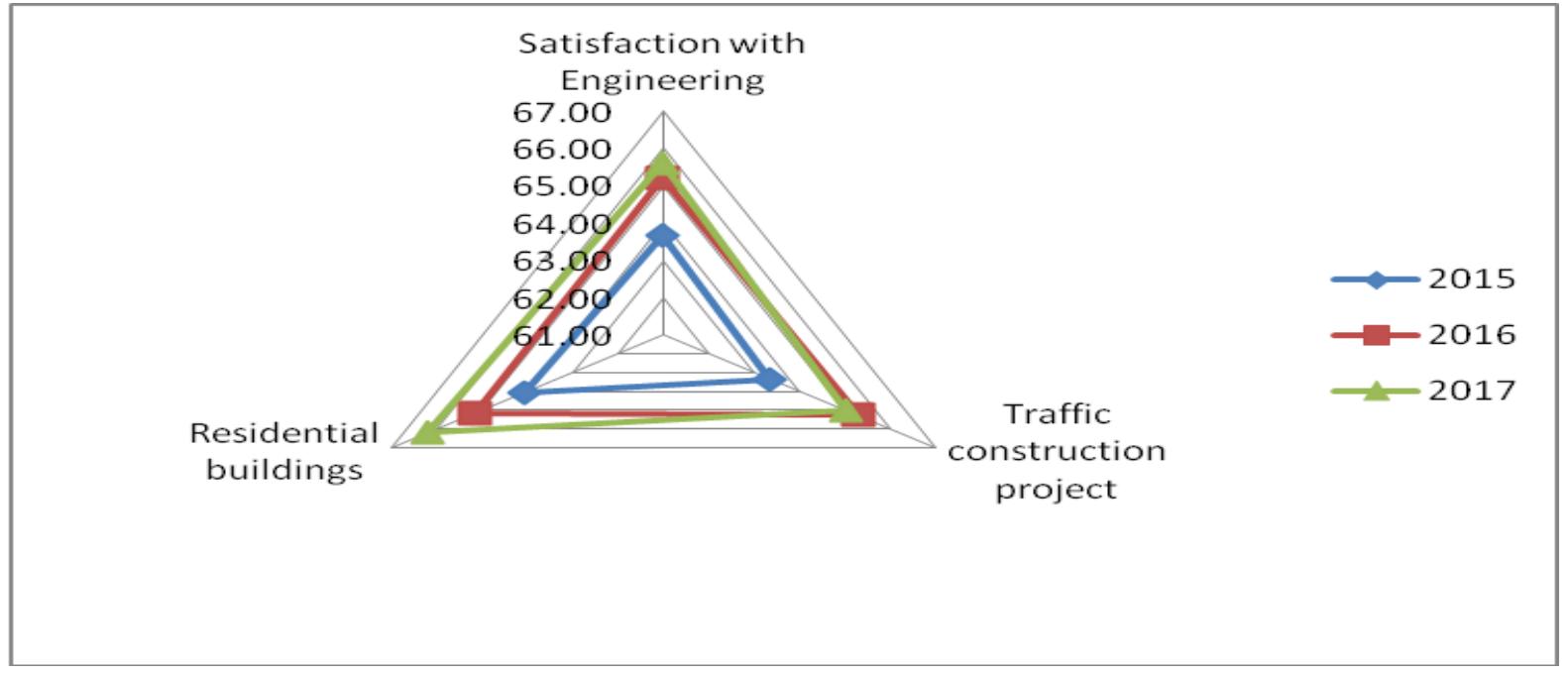

Fig. 3 Score of residents' satisfaction with engineering quality from 2015 to 2017

\section{Service Quality}

From 2015 to 2017, the score of satisfaction with service quality increased steadily from 59.25 to 63.71 . Among the specific items, the score of residents' satisfaction with short-distance public transportation was 65.65 in 2017, a $12.16 \%$ increase from 58.53 in 2015 . The long-distance public transportation service scored 65.02 in 2017 , a $9.33 \%$ increase from 59.47 in 2015. In addition, the scores of residents' satisfaction with logistics and express delivery service, insurance service, municipal public utilities service, primary and secondary education, old-age care, public cultural and sports service, housekeeping service, and medical service had been increasing year by year. However, scores of residents' satisfaction with e-commerce service and after-sales service had been dropping, and scores of residents' satisfaction with banking service and tourism service had not been quite stable. These are all alarming signs (Figure 4). 


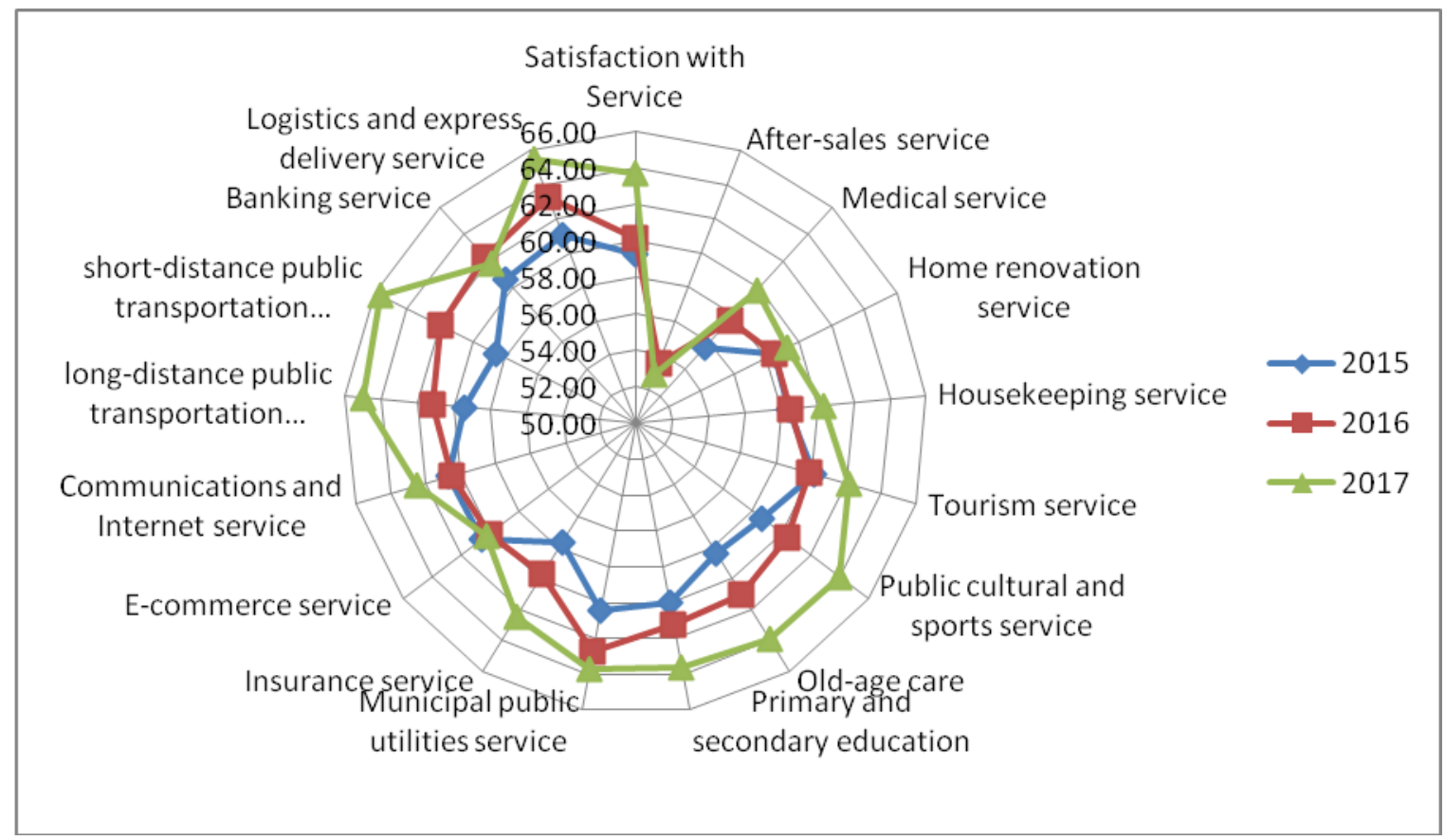

Fig. 4 Score of residents' satisfaction with service quality from 2015 to 2017

\section{Environment Quality}

When it comes to the environment, the score of residents' satisfaction with environmental quality increased from 53.99 in 2015 to 55.82 in 2017 . In 2015, the score of residents' satisfaction with air was 55.91, and water 52.07. In 2017, residents grew more satisfied with both air and water than in 2015, and residents had always been more satisfied with air than water (Figure 5).

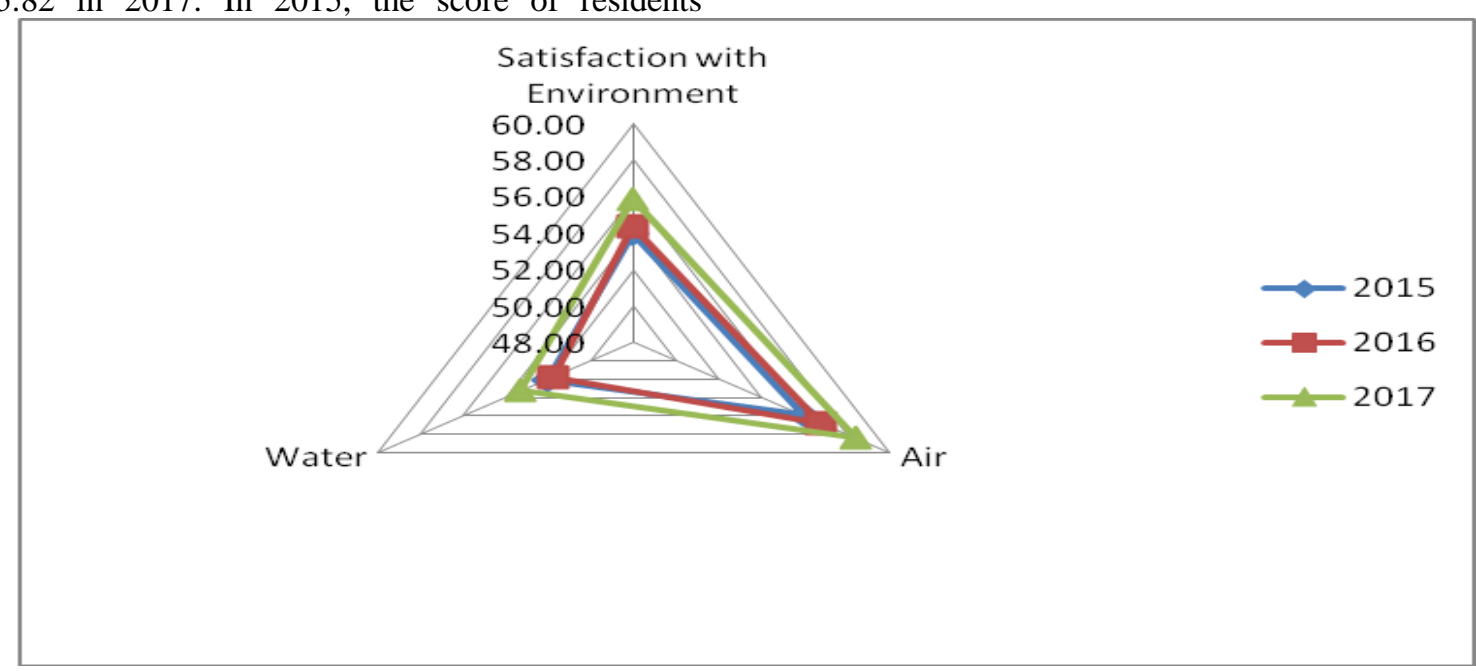

Fig. 5 Score of residents' satisfaction with environment quality from 2015 to 2017

\section{E. Quality Awareness}

The score of residents' quality awareness increased from 61.89 in 2015 to 67.20 in 2017 , growing by $8.58 \%$. Among them, residents' satisfaction with complaint settlement grew from 55.90 in 2015 to 74.22 in 2017 , an increase of $32.78 \%$. (Figure 6) 


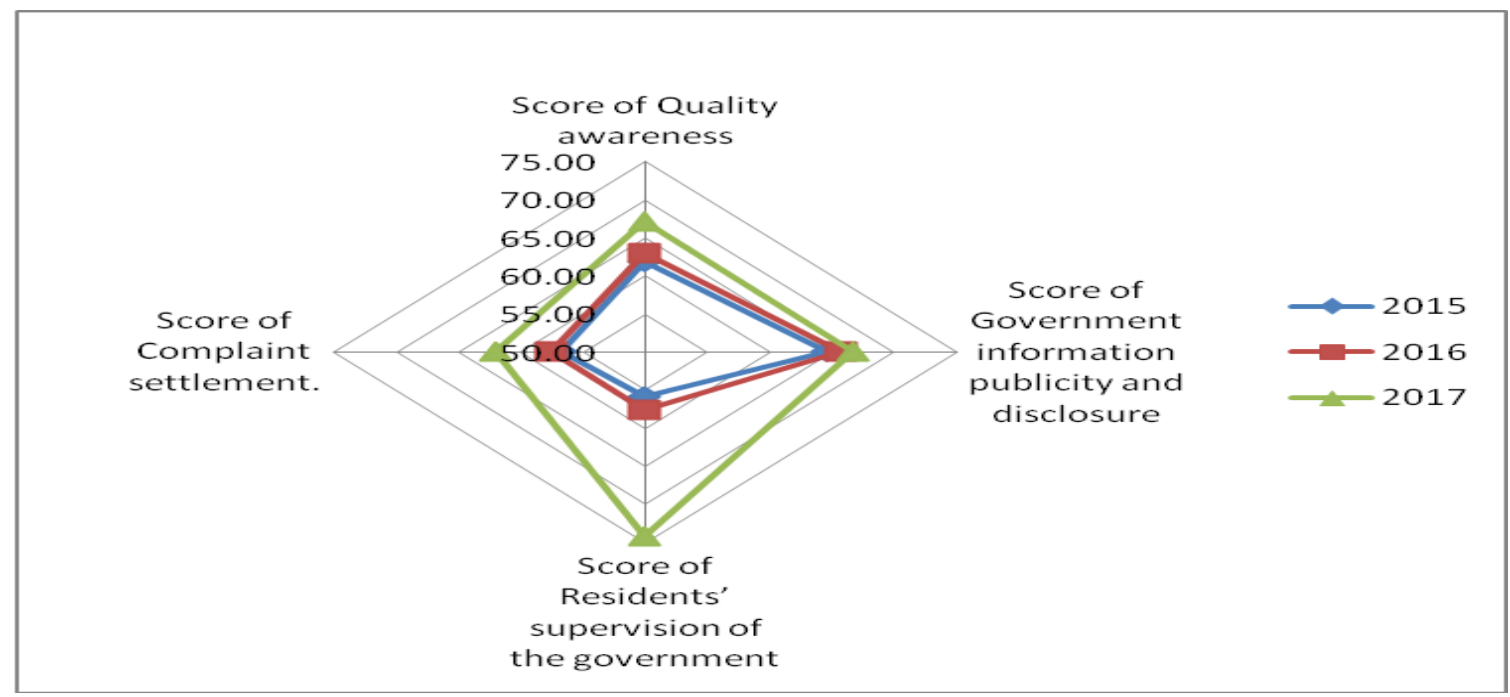

Fig. 6 Score of residents’ quality awareness from 2015 to 2017

\section{FINDINGS ABOUT DIFFERENT GROUPS}

\section{A. Degree of Satisfaction among Residents with Different} Educational Background

In 2015, residents with primary school diploma and below were most satisfied with the government, while people with master's degree or above were least satisfied. In 2016 and 2017 , residents with college education or undergraduate education were moderately satisfied with the government, while those with master's degree or above were less satisfied. Apart from people with master's degree and above, residents' satisfaction with the government improved significantly in 2017.

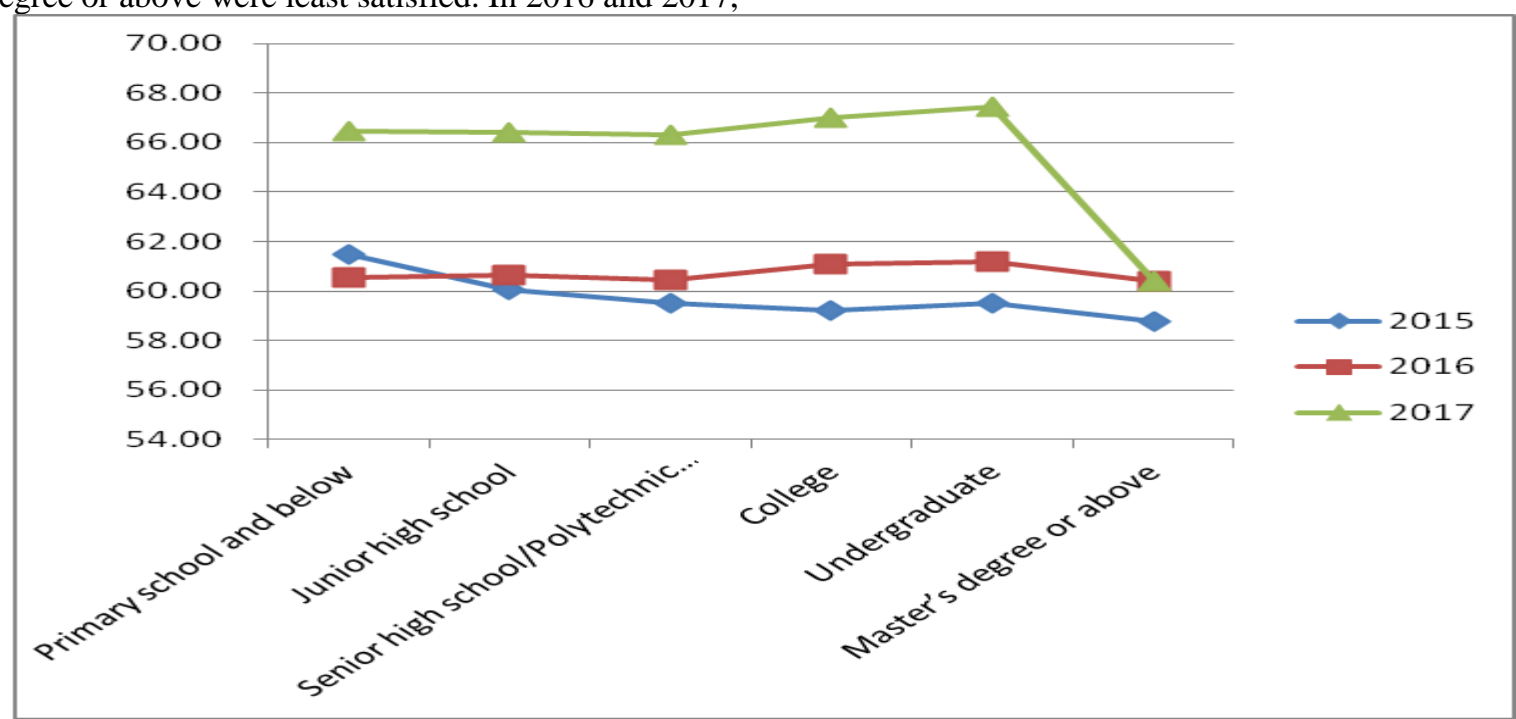

Fig. 7 Degree of satisfaction shown by residents of different educational background from 2015 to 2017

\section{B. Degree of Satisfaction among Residents of Different} Genders

and the degree of satisfaction among women were about 0.1 points higher than that among men every year.

Data show that from 2015 to 2017, both men and women had grown more satisfied with the government year by year, 


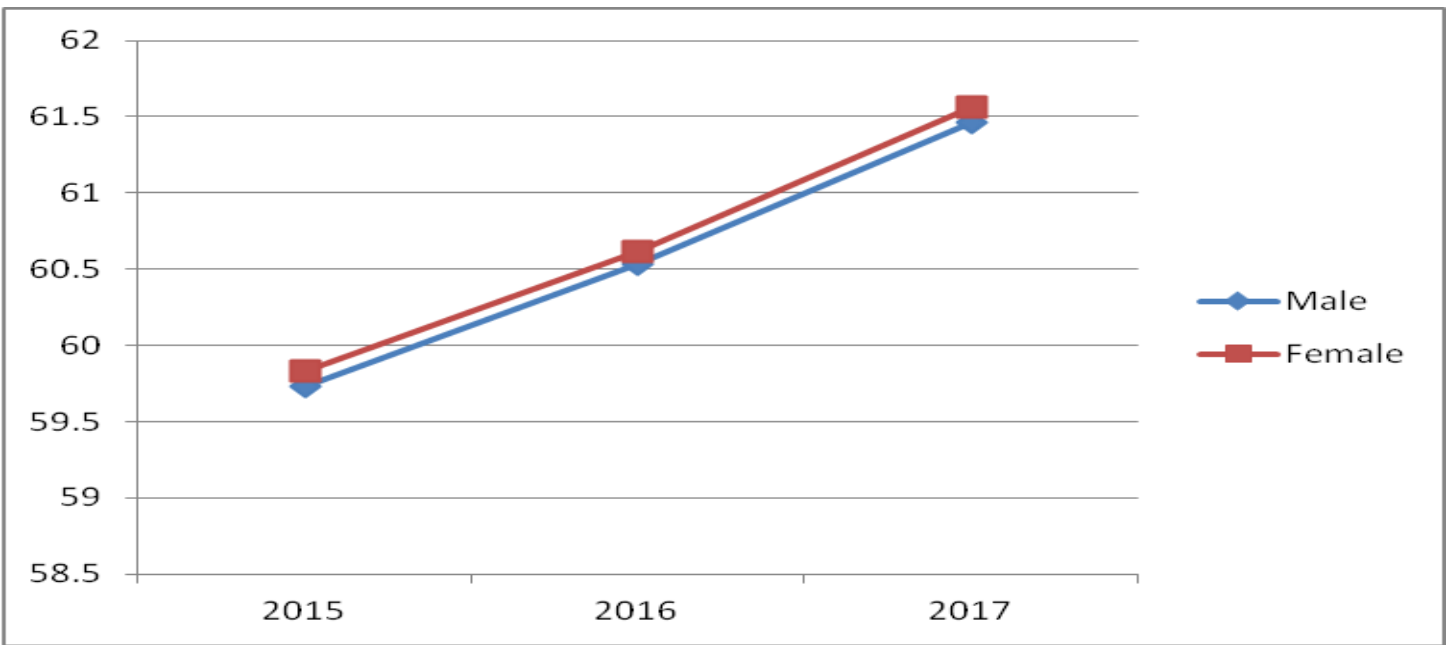

Fig. 8 Degree of satisfaction among residents of different genders form 2015 to 2017

\section{Degree of Satisfaction among Urban and Rural Residents}

From 2015 to 2017, although the degrees of satisfaction among urban residents and rural residents were both increasing year by year, urban residents were significantly more satisfied with the government than their rural counterparts.

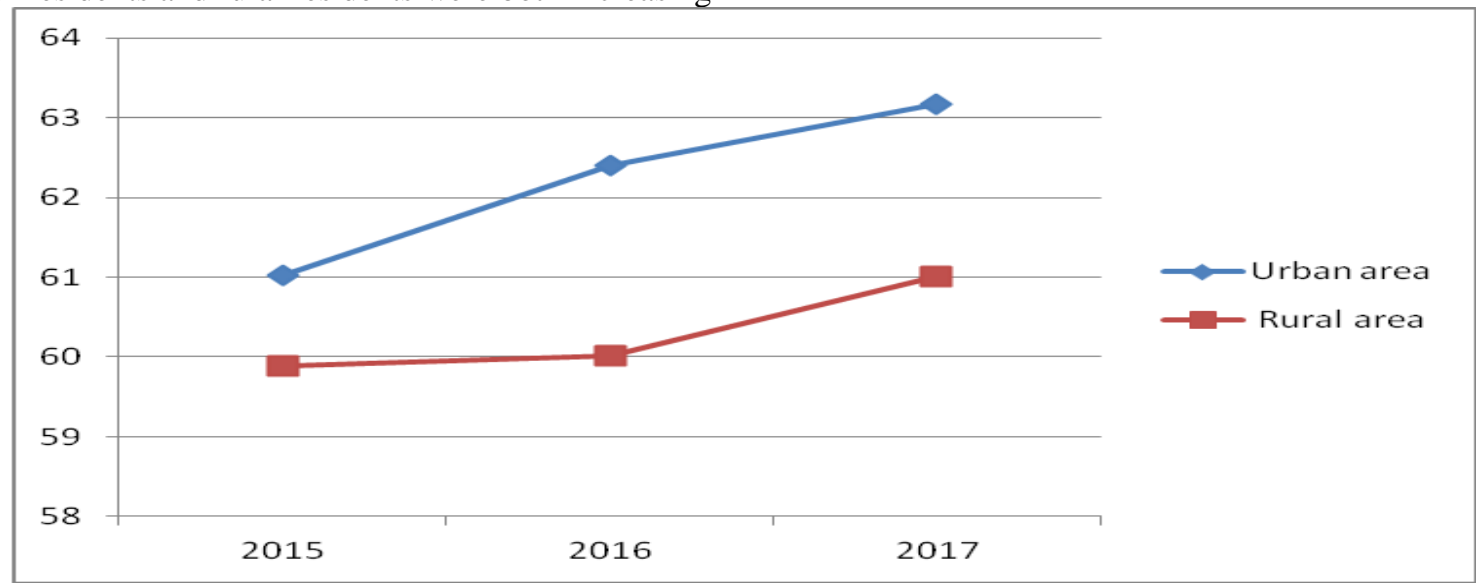

Fig. 9 Degree of Satisfaction among Urban and Rural Residents

\section{CONCLUSION}

A. Residents' satisfaction with the government had been growing for three years in a row.

The overall score of Chinese residents' satisfaction with the government was about 60 . The overall score as well as the scores of product quality, engineering quality, service quality, environmental quality and quality awareness had been steadily growing from 2015 to 2017. 


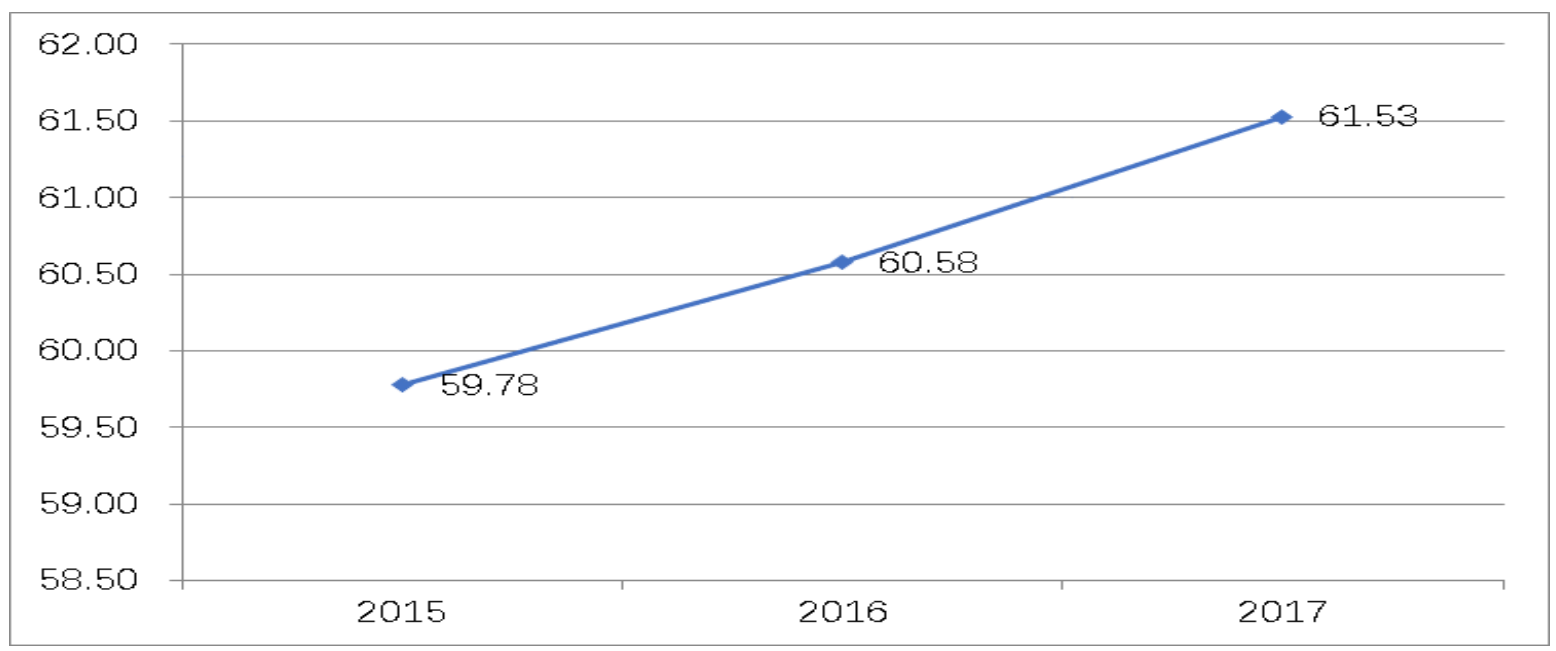

Fig. 10 Score of residents' satisfaction from 2015 to 2017

B. Poor Environmental quality has become a major cause of residents' dissatisfaction.

From 2015 to 2017, among five indicators, residents were least satisfied with the environment, which had become a major source of their dissatisfaction. Good water and air quality is the basic needs in residents' everyday life. For quite a long time in the past, environmental conservation was neglected when emphasis was given only to economic development characterized by high investment. With the growing awareness that "green environment is as important as gold" and the implementation of the strategy of ecological conservation, the environment had gradually improved. Therefore, residents' satisfaction with environmental quality had continuously improved.

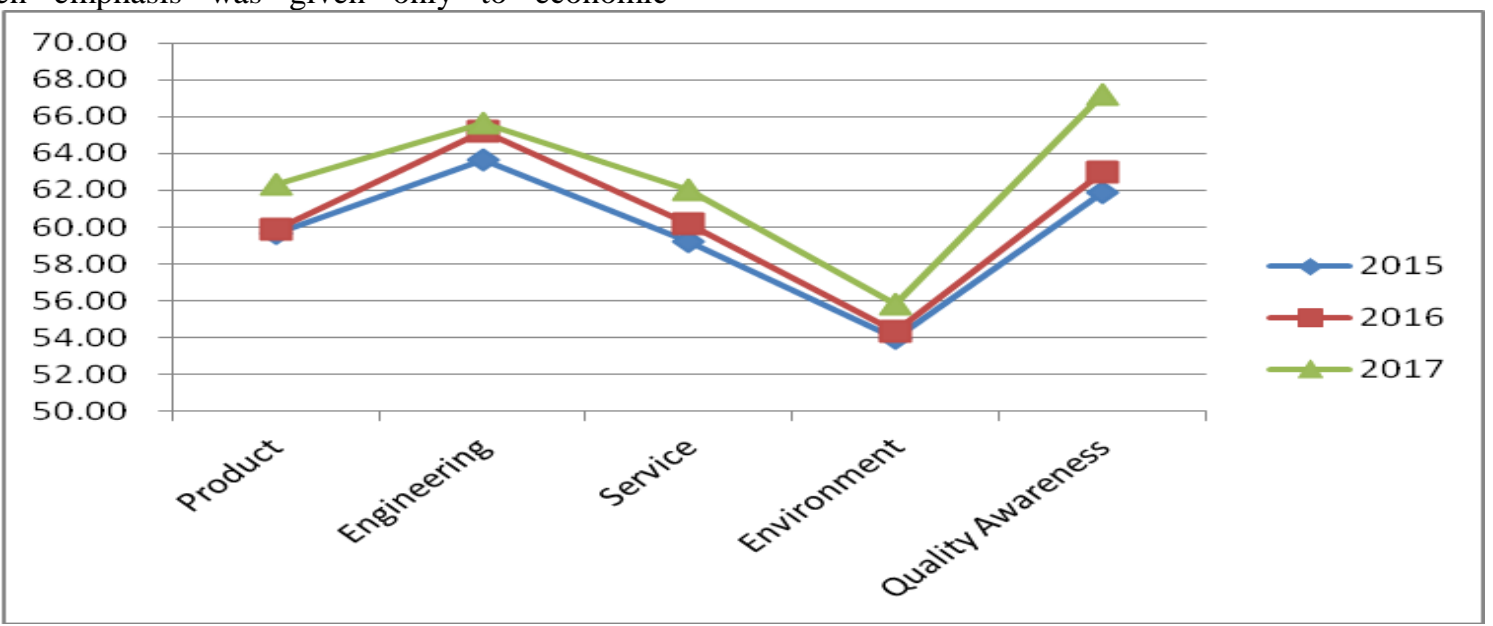

Fig. 11 Score of resident satisfaction from 2015 to 2017

C. There is a gap between urban and rural residents in the degree of satisfaction.

Data show that the score of satisfaction among urban residents in 2015 was 1.14 points higher than that of their rural counterparts. In 2016 and 2017, score among urban residents were 2 points higher than rural residents, showing an obvious gap.

\section{RECOMMENDATIONS}

To accurately pinpoint the growing material and cultural needs of residents, and to identify the focus and pain points of residents' needs, the following recommendations are proposed according to the results of the survey on the degree of residents' satisfaction with government work:

\section{A. Safeguarding and improving people's well-being is the} mission of government's fiscal policy.

The government should balance economic development and the promotion of people's benefits, continuously optimize the structure of fiscal expenditure, and reduce regular expenditures. The focus of government funds should be channeled to poverty alleviation, education, medical service 
and other areas pertaining to people's welfare so that people will have greater sense of fulfillment.

B. With the continuous advancement of urbanization, the government has channeled huge resources

disproportionately to urban areas for quite a long time.

As a result, education, medical and health service, and public services in cities are far better than those in rural areas. The government should seize the opportunity of implementing the rural revitalization strategy to readjust the unbalance between rural and urban areas by beefing up investment and support for rural areas.

\section{The contradiction between economic development and} environmental protection has existed for quite some time.

The efforts to improve the environment should be conducted step by step. Systematic and targeted pollution prevention and treatment measures should be put in place for different sources of pollution. It is necessary to help polluting enterprises formulate pollution rectification plans and schedules, and improve emission standards and rectification standards for polluters of different industries and different scales as soon as possible.

D. The government should speed up the establishment and promotion of complaint platforms, vigorously integrate multiple supervision platforms, put in place unified complaint channels, initiate telephone and WeChat complaint channels, and raise people's awareness of these channels.

With these efforts, people would get access to the channels of complaints when necessary, and get the feedback as soon as possible after filing a complaint. Consumers' personal safety and rights should also be effectively guaranteed.

The government should deepen institutional reform, coordinate and promote the construction of national quality infrastructure such as standards, measurement, inspection and testing, and lay a foundation for the establishment of the standard system for the emerging service industry, so as to facilitate the transformation of the economy from high-speed growth to high-quality growth.

\section{ACKNOWLEDGMENT}

This paper is supported by the National Key R\&D Program Product Quality Process Measurement Analysis and Improvement Technical Standards Research Project Item 5 "Development of Quality Basic Capability Evaluation Technical Standards" (Subject No. 2017YFF0206505).

\section{REFERENCES}

[1] E. Sandvik, E. Diener \&L. Seiditz, Subjective Well-Being: The Convergence and Stability of Self-Report and Non-Self-Report Measures, Journal of Personality, Vol. 61, No. 3,1993,pp.317-342.

[2] John F. Helliwell, Haifang Huang, How's Your Government-International Evidence Linking Good Government and Well-Being, British Journal of Political Science, Vol. 38, No. 4, pp. 595-619,2008.

[3] J.C. Ott, Government and Happiness in 130 Nations- Good Governance Fosters Higher Level and More Equality of Happiness, Social Indicators Research, Vol. 102, pp. 3-22, 2011.

[4] N. Joseph Cayer, Government Works: What Influences Success in Public Organizations, Public Organization Review, Vol. 4, pp.373-375,2004.

[5] Peiyi Lu, Ying Liang, Health-Related Quality of Life of Young Chinese Civil Servants Working in Local Government: Comparison of SF-12 and EQ5D, Applied Research Quality Life, Vol.11, pp.1445-1464, 2016.

[6] FengLei, Wu Shaopeng, Xiong Zheng, Analysis on the Survey of Quality Satisfaction Level in 2016, Standard Science, No.10, pp. 101-106,2017.

[7] Gang Chen\& Shu Li, How Government Let People Be Happy? An Empirical research on government quality affect people's Happiness, Management World, No.8,pp.55-67,2012. 